\title{
Towards a mature provision of vocational education
}

\author{
Dr Stephen Billett \\ School of Education and Professional Studies \\ Griffith University, Australia \\ S.Billett@griffith.edu.au
}

\begin{abstract}
Accounts and analyses of vocational educators' practice, provided through the contributions to this special issue, illustrate how centrally-generated and prescriptive policies and practices and those teachers' reactions to them have come to characterise contemporary vocational education. The application of often centralised institutional architectures, their measures and procedures, along with the quest for measurable outcomes, commonly appear to deny the diversity of interests, intents and capacities of those who engage with these provisions as students, apprentices and teachers. These centralised kinds of provisions then can generate tensions between those who seek to enact educational experiences (that is, teachers) and those who have devised the policies and practices that act as 'practice architectures' that both enable and constrain vocational educators' work. Rather than addressing the key global problem of the standing of vocational education, and its teachers and students, these centralised measures often seem to contribute to, reproduce, and sustain the low standing of vocational education and focus on securing institutional goals. In turn, this low standing beggars vocational education by limiting the capacity to engage teachers, students and industries, thereby undercutting its ability to fulfil its potential. The articles in this special issue reinforce the need for a mature vocational education system where teachers have the capacities and are granted the legitimacy to practice in ways that meet local needs and adapt to local circumstances in which they teach and their students learn. Instead of being pre-occupied with exercising the architecture of control and compliance, those in government and in industry might best direct effort to granting greater autonomy to vocational educators and by taking action to redress the poor societal sentiment towards vocational education through championing its worth and contributions.
\end{abstract}

\section{STANDING, TENSIONS AND PRESCRIPTION}

Beyond the seemingly perennial issue of the low standing and status of vocational education and training (VET), this special issue draws out two other issues that characterise contemporary provision in this important educational sector globally. The first concerns the difficulties that arise from the use of prescriptive, uniform and centrally-organised national educational arrangements that, because of their generality, are often poorly aligned with local needs and circumstances, and often unnecessarily constrain vocational educators' discretion and capacities of to be responsive to those needs and circumstances. In particular, such centralised arrangements often fail to account for the differences in vocational educational systems and provisions, the specificity of local requirements, the diversity of the needs and capacities of those who are to learn, and to be responsive to those differences, specificities and diversities through educational provisions. Secondly, there are inevitable tensions that arise between the imperatives of those who promote, order and organise VET provisions (including government, industry, and unions) and those who enact them (that is, vocational educators). These tensions are inevitable in systems where power and discretion sit asymmetrically alongside each other. These issues are directly addressed in this collection of papers, which illustrate and elaborate them individually and comparatively thereby highlighting the distinctions and diversity across vocational education systems and programs, including how transitions into and out of vocational education VET are ordered. In all, they bring 
compelling conceptualisations and evidence in making their respective cases. In doing so, they contribute to the growing argument that profound changes need to occur to secure effective vocational systems that are broadly responsive, inclusive of the range of goals, interests in and contributors to vocational education and the diverse circumstances in which it is enacted. That is: mature vocational education systems and provisions. These changes include promoting vocational education as a profoundly worthwhile sector that addresses distinctive economic and social contributions both to the life of societies and the lives of those it educates, and the progress of communities it serves, and also permitting vocational education and educators to fulfil its full potential, which includes realising the kinds of goals that its sponsors desire, participants want to learn and other assisting them learn.

Indeed, rather than ordering and monitoring arrangements seeking to secure uniformity and conformity, other more pertinent goals might be pursued by those who aim to organise and sponsor vocational education. These goals might include substantially elevating the standing within the community to be far higher and its esteem far stronger, the championing of the richness and importance of vocational education and the occupations, communities and individuals it serves. Then, there is the need to enhance the standing of vocational educators, sponsoring their selection and preparation, and granting them the kinds of professional discretion that will permit them to address localised needs, specific requirements and respond flexibly to needs of their students in generating the kinds of skills required by industries and employers, and by legislators and policymakers who are all commonly concerned about securing and sustaining highly skilled workforces.

It is these issues that are discussed within this short paper as a commentary on the contributions of these articles. It does this by, firstly, identifying issues associated with the standing and status of vocational education provisions where centralised control and top-down ordering have come to be seen as being appropriate and orthodox. Then, the findings from the other articles in this special issue are used to illustrate and elaborate how uniform and prescriptive frameworks, curriculum provisions and the centralised ordering of experiences fail to account for diverse local circumstances in VET. Thirdly, and again drawing on findings from the other contributions to this special issue, the consequences of this ordering are discussed in terms of the inevitable tensions between prescriptive demands of centralised agencies and those teachers and vocational educators who enact vocational education provisions. These contributions are made by drawing on findings from the articles and their accounts of these three issues and through them making the case for a more mature or vocational education systems. In such systems, central agencies are responsible for VET provision at the state or national level, but will (i) more effectively address broader issues associated with the standing and engagement of vocational education within the community, (ii) identify and build the relationship between broad statements of educational intents and the local means of achieving those intents, and (iii) provide the kinds of support needed for the preparation and practice of vocational educators in realising these goals. That preparation extends to granting discretion to vocational educators to make important educational decisions associated with achieving those goals at the local level and using their own professional expertise and judgments.

\section{The standing of vocational education}

Vocational education suffers from relative low standing in most countries when compared with higher education and even with the upper levels of secondary education (Billett, 2011). Even in countries where vocational education has a high profile, in Germany for instance, its relative standing is considerably lower than preparation for the professions through higher education (Hillmert \& Jacob, 2002) and is structured accordingly. In other countries, vocational education is often seen as being a less preferable option and even a last resort for school leavers who fail to achieve the grades from schooling required for entry to higher education (Deissinger, 2002). Consequently, there is often a relatively negative societal sentiment directed towards vocational 
education in many countries, perhaps most strongly felt where there is intense competition for educational achievement (as, for example, in merit conscious Singapore, or South Korea) or where it has been positioned institutionally as being potentially peripheral (as, for example, in the United States). This negative sentiment is deeply entrenched in many societies and has arisen through history and has been rehearsed and perpetuated over time, even centuries. Successive waves of societal elites (that is, aristocrats and theocrats) and, in more recent times, bureaucrats, have passed judgements on and made decisions about the standing of occupations, and on the education and the educators who prepare people to practise those occupations (Billett, 2011). Decisions about educational provisions made by these important others have served to secure and sustain the relative low standing not only of these occupations but also of vocational education. Most of this decision-making has been enacted in the absence of the voices of those who practice and those who learn and teach these occupations. Even when there were organisations able to speak on behalf of these occupations - in particular, the ancient guilds and modern trade unions - they have often been concerned with other priorities, such as the development and expansion of their own institutional power, and the wages and conditions of their members, rather with the standing and quality of occupational preparation.

A range of consequences arises from this standing, not the least being that 'powerful others' continue to make decisions about these occupations and the educational provisions that serve them. Those decisions are often shaped by ill-informed societal biases and sentiments, and have served to diminish rather than elevate understandings about the kinds of capacities that are required for effective occupational practice (see Billett, 2011). Two of these consequences are sharply evident in the body of work reported in this special issue. Firstly, there are the top-down, uniform prescriptions for practice that are described as (institutional) 'practice architectures' in some of the contributions. Much of the focus and emphasis in these prescriptions and the procedures used in attempts to realise them are about securing compliance through pre-specifying and managing the work undertaken by teachers, including specifying what will be taught and how it will be assessed. The overwhelming premise is that 'others' who are external to vocational education and the actual practice of occupations concerned know more than those who teach and their understandings and perspectives must predominate and be implemented with fidelity by those who teach in vocational education systems. The second consequence follows as a corollary of the first: it is evident in the tensions that arise between these prescriptive measures and the practices of teachers who enact vocational education provisions at a particular point in time, in particular circumstances, with the aim of meeting the needs of students with diverse backgrounds, readiness, capacities and interests. Moreover, these enactments take place within vocational education systems which were a product of particular governmental, institutional and national histories, each with their peculiarities and emphases. Yet, both national and global frameworks are seeking to order the provisions across these diverse and institutional bases, and in ways that perpetuate rather than challenge or redress this standing and/or the societal sentiments that reinforce it. Yet, in doing so they restrict the provisions from being responsive to some key concerns at the local level and are sometime pressed to enage practice architectures that disempowers rather than grants appropriate agency to those whooganise and enact vocational education provisions locally.

These societal sentiments are pervasive and enduring and some suggest that seeking issues of parity and comparability with other educational sectors is, therefore, almost impossible to achieve (Wolf, 2002). Yet, even if this is the case, there is the prospect of enhancing their relative standing and overall status. Such a goal seems possible given that the standing of vocational education differs across nation states. It seems to be far higher in countries such as Germany, Switzerland, Austria and some Scandinavian countries than in other countries, for instance the United Kingdom, USA and Australia. In those countries where the status is high there are cultural sentiments and practice (that is practice architectures) that value and promote skilled work and its preparation (Deissinger, 1994; Deissinger, 2002; Stevenson, 2005). Moreover, there is a concerns to support and sponsor the development of occupational skills and enage with vocational education to 
achieve these purposes that arises through beliefs about its worth. So, rather than pressing people to participate in and support vocational education, it enjoys legitimacy and sentiments of worthiness which are endorsed by personal, enterprise and industry commitments. Fundamentally, these differences suggest that the status of vocational education is neither fixed nor resistant to being changed. Therefore governments, other national agencies as well as supra-national agencies (for example the OECD, European Union etc) could play roles in bringing about changes that elevate that status.

Noteworthy here is that changes in these kinds of sentiments arise through national policies and actions. It is acknowledged, for instance, that in the post-war period two countries (i.e. Germany and Japan) did much to change their national circumstances through promoting the importance of skilled work, albeit through quite different means. Germany developed and through dual apprenticeship arrangements and Japan through adopting Deming type reforms (Sennett 2008). Given that sentiment which views occupation served by vocational education and that provision of education as being of low standing leads to resistance by parents and young people, and even school educators, from participating in or with it, for this reason alone enhancing the standing and status of these occupations and their educational provision would be worthwhile (Lum, 2003). Also, there is the important role that vocational education plays in preparing people for occupations that are so fundamental to the continuity and advancement of our countries and communities' continuity (Billett 2011). Part of the salience of these provisions is associated in the breadth of those who participate in vocational education. For instance, in Australia often represent a far broader body of students than found those who participate in higher education in terms of ages, ability and purposes for studying (Billett, 2000), and one in eight people engaging in its provisions. Also, the range and kind of provisions within vocational education are often far more diverse than those encountered within schooling, for instances, and often across a far wider set of levels of achievement (e.g. from low level certificates to higher diploma level qualifications). All of this makes the work of vocational educators as being at least as demanding as those in other sectors. Hence, there is a need for vocational educators to be carefully selected, prepared, rewarded and permitted to practice in ways that allows them to meet the needs of the diverse student body as directed towards developing the kinds of occupational capacities which those students want to learn, and their employers need to be learnt.

Given the above, and what follows, it is perhaps worth noting some of the practices utilised within the Finnish schooling system, which is broadly acknowledgement as a highly successful schooling system and both respected and envied across the world. When asked what makes the system so effective, Sahlberg (2012) states that well-educated teachers are the key component. He refers to the importance of building a core of highly trained teachers and building the teaching profession to be a high status and valued occupation. He even goes so far as to suggest that the standing of being a primary school teacher is pretty close to how you would describe that of a medical practitioner (Sahlberg 2012 ). Indeed, he proposes the effectiveness of this education system is premised on Finnish teachers' practice, which is characterised by autonomy, responsibility, independence and respect. In this way, the organisational architectures of the Finnish education sector promotes effective practice architectures in ways that seem quite distinct with what has been discussed within the contributions to this special issue. In contrast to much of what has been advanced in these contributions, Sahlberg referred to effective educational provisions not being prescriptive, but emphasising local decision-making with teachers and administrators being highly valued and, importantly, with the responsibility for learning also being largely vested with students. It is curious that in an era when governments make much of comparisons of educational performance across nation states and rank that performance globally, that the lessons learned from this most highly performing of educational systems are not considered when changes are made to the institutional architecture of educational provisions. Yet, as reported here, it is a very different kind of institutional architecture that shapes much of the intended vocational education provision and how it is enacted. What most of these articles suggest is that the institutional architecture is 
quite broadly cast and emphasises regulation and compliance, and places limits on the practices of teachers.

\section{Imposition of regulatory processes}

As described in the contributions to this special issue and reflecting a seemingly orthodox approach adopted for the ordering and organisation of vocational education globally, institutional structures and architecture are often premised on securing compliance to centrally-generated mandates and requirements. These structures comprise uniform processes and pre-specified outcomes and mechanisms directed towards securing national social and economic goals. Securing uniformity and adherence to prescribed outcomes has become an abiding concern of governments and supranational agencies. The development of national (e.g. Australian Qualification Framework, German Qualification Framework) and cross-national qualification frameworks (e.g. European Qualification Framework) with their attendant requirements for courses to be organised and recognised and outcomes pre-specified and stipulated has led to an intense focus on the management of this educational provision focussed on compliance to these mandates. Processes of registration, accreditation and compliance often feature in these arrangements, as exampled by, but not restricted to the Australian experience. Yet, these arrangements usually have no means of accounting for or incorporating differences at the local level, diverse institutional arrangements or student needs at the point of implementation (Billett \& Hayes, 2000, Berglund \& Loeb 2013). Similarly, Brennan Kemmis and Green (2013) refer to these structures as having strong framing and rigid classifications that makes impositions on how teaching within vocational education should progress. These kinds of measures are exemplified in Swedish quality assurance scheme that not only commodifies the educational provision, but also seeks to shape teachers' actions of in ways not always consistent with achieving its own goals of being client-focussed, because of its rigidities (e.g. not giving students extra time when they fail) (Warvik 2013), which privileges administrative and institutional imperatives.

Much of this institutional framing and architecture is about securing uniformity and fidelity with the intended curriculum (i.e. what sponsors intend will be learnt) and similar mechanisms are adopted across a range of countries to achieve this end. These mechanisms are usually in the form of prescriptive educational outcomes, processes for realising those outcomes that sometimes extend to modularised units of instruction, and prescriptions about teaching and assessment practices. The articles in this special issue report a range of requirements for educational intents and institutional arrangements (Brennan Kemmis \& Warvik, 2013), such as the very distinct school-based apprenticeship model that (Berglund \& Loeb, 2013) report. The differences associated with educational intents extend to some systems key national imperatives such as citizenship education (e.g. Sweden) or engaging and preparing migrants for employment and working life (e.g. The Netherlands). These differences also extend to fundamental commitments such as state funded educational provisions (i.e. Denmark, Sweden, Finland) through to those which are oriented to feepaying provisions (e.g. Australia, United States etc). Issues associated with institutional arrangements also differ across those where what are referred to as apprenticeships are taken almost wholly within workplaces or are based within high schools (Berglund \& Loeb, 2013). In his paper, Jorgenson (2013) sets out the distinct qualities of a dual approach to apprenticeship and its particular institutional architecture which includes social partners centrally in the process in ways a school-based provision does not. The extent of the differences brought about by these arrangements potentially run deep. For instance, it is quite likely that young people engaged in apprenticeship arrangement based largely in workplaces will not come to identify as students, but instead as nascent workers. Hence, they are more likely to seek statements that endorse their standing and capacities within their work setting and through their work than their studies in schooling settings. Conversely, young people who are largely students within educational programs and who only venture periodically into workplaces are more likely to view themselves as students 
and seek to have their capacities recognised and affirmed by their school-based performances (tests, assignments etc).

Consequently, quite likely these distinctions also play out in terms of how these learners direct their energies and agency in learning through activities in both settings, which likely extends to the bases by which they do so and also how they come to identify themselves. For instance, as Jorgenson (2013) notes, the key reason Danish dual sector apprenticeships drop out is that they lose interest. Perhaps in earlier times these young people might have felt pressure to remain in these programs, but less so in contemporary times. These school-based apprenticeship arrangements lend themselves to other kinds of distinctions and peculiarities. For instance, with the Danish schoolbased apprenticeship model there are arrangements for student to alternate (i.e. swap) workplaces during their practicum which is far less likely to occur when apprentices are employees in one workplace. Similarly, apprentices as students are reported as being rejected by their workplaces because they are immature, which is perhaps less likely when they are employed as apprentices. So, these distinct set of institutional arrangements (i.e. apprentices as students versus apprentices as employees) likely lead to very different kinds of engagement by and outcomes for these learners.

Sitting behind these bases of engagement are what individuals come to view as their vocation: the occupations and forms of work with which they wish to identify. So, whereas occupations are societal facts, individuals need to assent to an occupation becoming their vocation (Billett 2011). This assent is a personal fact. That is it, something shaped by personal interests and intentionalities: how individuals come to direct their time and effort. As Jorgenson (2013) notes, these actions and associations are central to students' and apprentices' engagement in vocational education programs. He also, identifies ways in which contemporary students may act to postpone making a decision about entering the labour market, or selecting a preferred occupation and extend the transition period between school and post-school options. So, whilst these arrangements for delaying occupational choice exist as part of the institutional provisions, they are engaged in diverse ways and purposes by young people. So again, these architectures are not wholly compelling and are able to be negotiated. As he suggests "(student) Choices and strategies are increasingly considered as provisional and temporary" (page X) There are also a range of other factors associated with the students, and their readiness to engage in vocational education that are inherent elements of these provisions and systems. What is suggested in this article is that not all of these students are ready for independent and self-directed styles of learning. So, assumptions that might be made about a particular cohort of students may not apply uniformly across them. Instead, there may well be particular kinds of instructional practices and needs to be addressed. Although not explicitly stated in Grevholm and Lindberg's (2013) manuscript on mathematics, it can be imagined that a diverse student cohort will bring a similar range of readiness to engage in studying mathematics.

Also evident in the contributions to this special issue is the necessity of, but also differences in teacher decision-making. That is, teachers need to make decisions about how and what they teach, and those decisions arise daily in the preparation and enactment of teaching. However, the personal-professional practices of teachers will shape the nature of that decision making in ways which go beyond the scope of institutional architecture. For instance, those teaching in occupational specific programs often have significant workplace experience and are themselves occupational experts, and this experience extends to their particular valuing of practice-based activities (Brennan Kemmis \& Green, 2013). In this way, these teachers come to privilege particular kinds of knowledge, and have specific ways of engaging with and knowing how they practice. Yet, as both Berglund and Loeb (2013) and Grevholm and Lindberg (2013) report, other teachers see themselves as educators first and foremost, have experience largely within educational institution and exercise quite different views about the goals for and processes of their students' learning. Many of these teachers do not have the workplace experience that is often held by adult and vocational educators. Yet, even within these teachers, there are those with particular specialisms. For instance, the study referring to teaching of mathematics indicates a key tension between teachers whose mathematics education is being applied more generally and those who see it as being more closely associated with a particular 
occupational practice (Grevholm \& Lindberg, 2013). Hence, the purposes for maths educational provisions can be quite diverse as would the means of teaching and assessing it.

So, the concept of practice architectures referred to in a number of the contributions above is likely enacted in different ways as shaped by institutional factors (e.g. kinds of programs, teachers, students) and personal and professional practices. Yet, at another level, there are concerns that goals and preferred processes of particular occupations stands as those which sponsors are keen to secure for the continuity of that occupational practice. There is also the practice architectures associated with a particular workplace that make specific demands about the kinds of qualities required from vocational education programs, and the employability of graduates. Then, there are the practice architectures of the particular educational institution that can differ widely depending upon whether the vocational education provision is to be largely institutional-based or enacted partially or substantially outside of the educational institution (i.e. in workplaces). Then, there is also a consideration of students' practices: their approach to and means of enacting educational provisions. So, all of these considerations emphasise the importance of practice architectures occurring at a range of levels and these all health influences on the provision of vocational education and how it is enacted, and for the students at least, how it is experienced. Yet, in terms of the enacted vocational education curriculum, perhaps most centrally placed here is the decision-making and discretion of those who teach.

\section{Teacher discretion versus institutional imperatives}

A theme repeated often across the contributions to this special issue (e.g. Brennan Kemmis \& Green, 2013, Warvik, 2013) and elsewhere in the literature is that the kind of processes and institutional architectures being adopted in countries such as Australia and Sweden can restrict teachers' discretion and professionalism and leads to tensions between what sponsors intend and what teachers want to enact. Indeed, this is part of their intent: to control and manage what is taught and learnt (Jackson, 1993). All of these issues come down to the degree by which it is possible and reasonable for vocational educators to be able to exercise discretion in that practice. However, this is a fairly complex issue in balancing professional autonomy against employer expectation. Teachers, as an occupation, are almost always employed by somebody else, perhaps unlike many other professions. As Skilbeck (1984) notes, there are very few instances where teachers have formed educational institutions and advanced particular sets of educational ideas on the basis of professional and autonomous practice. Instead, teaching is largely undertaken within institutions that have set of priorities, particular goals and provisions, and quite often, preferred approaches for instruction and assessment. Moreover, those who employ them are usually either the state or religious orders. In this way, and on the one hand, teachers as a profession are largely employed to achieve the goals of those institutions. Both of these kinds of institutions have clear mandates to exercise the reasons they establish educational institutions and their sponsorship of programmes within those institutions. In this way, teachers are constrained by the scope of these institutional arrangements, and, perhaps, legitimately so. Perhaps not surprisingly, much of the direction and intentions of programmes within education institutions are directed towards achieving these mandates. Moreover, as Skilbeck (1984) also noted, teachers are not the only stakeholders in making decisions about education. Instead, there are members of the community, and those who use the kind of education that education provides as well as students themselves. Indeed, Skilbeck (1984) pointed out that although educators do not have a legitimate right for monopoly on educational decision-making simply because they are teachers.

However, on the other hand, the literature on be adoption of innovation (i.e. how practitioners come to accept and implement change) suggests unless they are engaged with the kinds of contents and processes that they are to teach and their concerns about meeting students' needs are addressed, it is quite likely that the intentions of sponsors will not be met or with quite limited fidelity. That is, that honouring of the sponsors intents will be superficial, because of the moral and professional concerns of educators (Estola, Erkkilä \& Syrjälä, 2003). At least part of this 
need to act and to exercise discretion is because the work of vocational teachers is so "complex, multifaceted and much more than the narrow definitions of competency that are the bases of many training reforms in Australia and internationally" (Brennan Kemmis \& Green, 2013 p X). Moreover, as (Warvik, 2013) notes, these practices are constantly changing and transforming, with much of the mandates driving change being driven by those who are remote from the circumstances where vocational education is enacted. Hence, it is again these teachers who seek to reconcile these changes with what they know, how they currently practice and the circumstances in which they seek to practice (Vähäsantanen, et al, 2008). It follows then that, conceptions associated with how individuals (e.g. vocational educators) come to think and act in practice are increasingly associated with how they make sense of or decide to act in those circumstances which is often shaped by their earlier experiences. The term used elsewhere to capture this concept of how individuals come to engage, make sense of what they experience is individuals' personal epistemologies (Billett, 2009). More than these being sets of beliefs or concepts they also extend to how individuals go about achieving goals such as through their work as teachers or as students or apprentices in an educational program. It is these issues of everyday decision-making that are central to the process of enacting vocational education provisions that are reported by vocational educators as needing to be addressed in the everyday practice (Brennan Kemmis \& Green, 2013). Moreover, Warvk (2013) suggests that teachers are also positioned as agents of change. Yet, how affective will such agents be when their commitment to these changes is unclear, ambiguous and their sense of capacity to bring about change in their own and others practice may well be quite limited?

Hence, although Brennan Kemmis and Warvik (2013) claim the ideas of central planning and Taylorist rational organisation have been abandoned in scientific discourse, they seem to be the mainstay of much contemporary organisational discourse and practices in vocational education. Indeed, these practices seem to comprise the institutional architecture of vocational education systems across the globe. However, the critique here is that the intentions of sponsors will never be fully realised unless teachers are sympathetic to and enthusiastic about securing those outcomes. Indeed, the change literature suggests that even more than these factors, teachers' commitment arises through them having competence to enact and enjoy success with innovations. So, centralised agencies cannot confidently assert that what they propose will be successful and effectively implemented, the very basis of teachers' commitment to these initiatives will be premised on those teachers' capacities to effectively implement them (Mclaughlin \& Marsh, 1978). Yet, much of this lesson appears to have been lost or never considered within the institutional architecture of vocational education. This architecture has increasingly privileged and unmediated the role of external spokespersons (i.e. the voice of industry) and attempts to codify their demands through pre-specified learning outcomes and mandated content, in ways reminiscent of Taylorist sentiments and practices. In essence, the effort has been to 'teacher proof' the provision of vocational education (Stevenson 2001). However, for the kinds of reasons set out above, this process is unlikely to be helpful or feasible. Beyond the problematic issue of faithful delivery of what is intended through curriculum documents (e.g. syllabuses, training packages) and national standards for occupations, the contributions here also outline a range of other factors in the form of different kinds and levels of practice architectures and how agents such as teachers and students engage with them that make such mandations and prescriptions unworkable. The attempts in this special issue to illustrate and elaborate these perspectives are, therefore, particularly helpful. It is in setting out of these concerns, tensions amongst what sponsors want, practice architectures and how those who are to enact them construct their practice seems most timely, which highlight the kinds of complexities which cannot simply be addressed through top-down and prescriptive approaches that comprise much of the institutional architecture. Brennan-Kemmiss and Green (2013) rehearse and illustrate the nature of teacher decision-making which occurs as part of professional practice as something that can never be absent in the educational process. Indeed, what is proposed here suggest that teach decision-making is made more complicated by having to negotiate mandated and 
prescriptive measures than if they are able to exercise their professional practice in more unbridled, but negotiated ways.

\section{Towards a mature vocational education provision}

From the contributions to this special issue it is possible to propose that the kinds of institutional and practice architectures to which Kemmis and Grooteboer (2008) refer have profound, but not always productive outcomes for vocational education systems. Indeed, a highly regulatory approach that is founded on concerns about securing compliance may work directly against the effectiveness of these architectures, the work of teachers and the project of assisting students' learn the desired kinds of educational goals that are robust (i.e. can be applicable both situationally and be adapted to be applicable elsewhere. It is suggested that instead of ordering and monitoring arrangements which seek to vainly secure uniformity and conformity through processes that will be ineffective, other and more constructive processes and worthwhile goals might be pursued through such central agencies. These goals include elevating the standing of vocational education, its teachers and students within the local and national community. This might be achieved by the sponsors championing the richness and importance of vocational education and the occupations it serves, the provisions of vocational education and the potentiality of the students. Following from Salhberg (2012) it seems there is the urgent need to elevate the standing of vocational educators, sponsor their selection and preparation and grant them the kinds of discretion that will allow these educators to exercise discretion in best meeting the needs of their students, and the kinds of skills required by those who employ and those seeking communities, regions and nations to have highly skilled workforces.

That is, institutional architecture might be directed for different purposes and very different ways than currently. Central to all of this is the granting of more discretion to vocational educators to address problems arising at the local level and to be generative of educational experiences and provisions that will achieve the kinds of outcomes that both students and employers want. In many ways, much of this happens already, albeit subversively, as teachers seek to close the gap between the content and practices that are mandated and regulated and their perceptions about how experiences for students need to be organised and enacted. Of course, this is not to propose an 'anything goes' approach to teaching and the support of learning, nor the assessment of occupational knowledge. There are clear and justifiable needs for occupational standards to be met and through valid and reliable means so that students can generate the occupational knowledge they want to learn and be aligned with what employers want learnt, and also so that those who consume the goods and services they provide can be confident that these are supported by sound occupational practices. So, within legitimate constraints, there is a need for greater autonomy, selfregulation and professional judgement to be exercised by vocational educators in addressing student and other needs in the circumstances of their enactment. All of these concerns are well rehearsed, illustrated and made evident through the contributions of this special issue.

\section{References}

Berglund, I., \& Loeb, I. H. (2013). The rennaisance or a backward step: Disparities and tensions in two new Swedish pathways in VET. International Journal of Training and Research.

Billett, S. (2000). Defining the demand side of VET: Industry, enterprises, individuals and regions. Journal of Vocational Education and Training, 50(1), 5-30.

Billett, S. (2009). Personal epistemologies, work and learning. Educational Research Review, $4210-$ 219.

Billett, S. (2011). Vocational Education: Purposes, traditions and prospects. Dordrecht, The Netherlands: Springer.

Billett, S., \& Hayes, S. (2000). Meeting the demand: The needs of vocational education and training clients. Adelaide: National Centre for Vocational Education Research.

Brennan Kemmis, R., \& Green, A. (2013). Vocational education and training teachers conceptions of their pedagogy. International Journal of Training and Research. 
Brennan Kemmis, R., \& Warvik, G.-B. (2013). editorial. International Journal of Training and Research.

Deissinger, T. (1994). The Evolution of the Modern Vocational Training Systems in England and Germany: a comparative view", . Compare A Journal of comparative education, 24(1), 17 36.

Deissinger, T. (2002). Apprenticeship systems in England and Germany: decline and survival. Paper presented at the Towards a history of vocational education and training (VET) in Europe in a comparative perspective, Florence.

Estola, E., Erkkilä, R., \& Syrjälä, L. (2003). A moral voice of vocation in teachers' narratives. Teachers and Teaching: theory and practice, 9(3), 239-256.

Grevholm, B. E., \& Lindberg, L. M. (2013). Mathematics in VET programmes: the tensions associated with reforms in Sweden. International Journal of Training and Research.

Hillmert, S., \& Jacob, M. (2002). Social inequality in higher education; Is vocational training a pathway leading to or away from university? European Sociological Review, 19(3), 319-334.

Jackson, N. (1993). "If competence is the answer what is the question?' Vol.1, no.1, pp.46-60." Australian and New Zealand Journal of Vocational Education Research 1(1): 46-60.

Jorgensen, C. H. (2013). The role and meaning of vocations in the transition from education to work. International Journal of Training and Research.

Lum, G. (2003). Towards a richer conception of vocational preparation. Journal of Philosophy of Education, 37(1), 1-15.

Mclaughlin, M. W., \& Marsh, D. D. (1978). Staff Development and School Change. Teachers College Record, 80(1), 69-94.

Sahlberg, P. (2012). Finnish Lessons: What Can The World Learn From Educational Change in Finland. New York, Teachers College Press.

Sennett, R. (2008). The Craftsman. New Haven \& London, Yale University Press.

Skilbeck, M. (1984). School based curriculum development. London: Harper and Row.

Stevenson, J. (2005). The centrality of vocational learning. Journal of Vocational Education and Training, 57(3), 335-354.

Stevenson, J. (2001). "Vocational knowledge and its specification " Journal of Vocational Education and Training 53(4): 647-662.

Vähäsantanen, K., Hökkä, P., Eteläpelto, A., Rasku-Puttonen, H., \& Littleton, K. (2008). Teachers' Professional Identity Negotiations in Two Different Work Organisations. Vocations and Learning, 1(2), 131-148.

Warvik, G.-B. (2013). The reconfiguration of adult education VET teachers: Tensions amongst organisational imperatives, vocational ideals and the needs of students. International Journal of Training and Research.

Wolf, A. (2002). Does education matter? Myths about education and economic growth. London: Penguin. 